\title{
Caracterización de Neonatos en condiciones de exposición y padecimiento al SARS-COV 2
}

\author{
Ana L. Peña Ramírez \\ analu262002@yahoo.com \\ Ruth Liliana López Cruz \\ referente.neonatos@subredsur.gov.co \\ José Néstor Suárez S. \\ investigacionsrs@gmail.com \\ José Alejandro Mojica Madera \\ josemojica99@yahoo.com.mx \\ Laura Liliana Durán \\ enfermerasubredsur@gmail.com \\ Bogotá. Colombia
}

Sub Red Integrada de Servicios de Salud Sur E.S.E.

\section{RESUMEN}

Con el objetivo de describir una serie de Neonatos en condiciones de enfermedad por coronavirus 2019 (COVID-19), en el periodo de tiempo comprendido desde la semana epidemiológica 23 a 32 y 51 a 53, atendidos en una institución Pública de Salud de III nivel de complejidad en Bogotá, D.C. se presenta la caracterización epidemiológica y clínica, evidenciando correlación entre Peso al nacer y Edad gestacional( $R=0.85)$, con un promedio de edad de 30 días (IC95\%: 17,94-42,29) ( $\mathrm{p}=0.98)$ y estancia en días de 8,9. Predominio del Grupo 0 Positivo y género masculino (52\%). El reporte es la primera experiencia en el manejo de pacientes con diagnóstico de la COVID-19 en Colombia.

Dentro de los hallazgos al examen físico el más frecuente fue la presencia de desaturación, con una saturación promedio sin oxígeno suplementario de $84 \%$, los otros signos vitales fueron normales al igual que la perfusión distal, lo que indica que ningún paciente presentaba un compromiso severo a su ingreso. En el hemograma la única alteración encontrada fue la presencia de monocitosis con un promedio de monocitos del $12,11 \%$ (IC 8.78 - 15,45), la PCR no mostró alteraciones, siendo negativa con un valor promedio de 0.32 (Punto de corte: positiva > 0.4).

Palabras clave: Síndrome Respiratorio Agudo; Virosis; Infecciones por Coronavirus; Pandemias; Neonatos. 


\title{
Caracterización of Newborns under exposure and suffering conditions to SARS-COV 2
}

\begin{abstract}
With the aim of describing a series of Newborns in conditions of coronavirus disease 2019 (COVID-19), in the period of time from epidemiological week 23 and 32 attended in a Public Health institution of III level of complexity in Bogotá, DC, epidemiological and clinical characterization is presented, showing correlation between birth weight and gestational age $(\mathrm{R}=0.85)$, with an average age of 30 days (95\% CI: 17.94-42.29) (p= 0.98 ) and stay in 8.9 days. Predominance of Group 0 Positive and male gender (52\%). The report is the first experience in the management of patients diagnosed with COVID19 in Colombia.

Among the findings on physical examination, the most frequent was the presence of desaturation, with an average saturation without supplemental oxygen of $84 \%$, the other vital signs were normal, as was the distal perfusion, which indicates that no patient was severely compromised upon admission. In the hemogram, the only alteration found was the presence of monocytosis with an average of $12.11 \%$ monocytes (CI 8.78 - 15.45), CRP did not show alterations, being negative with an average value of 0.32 (Cut-off point: positive>0.4).
\end{abstract}

Keywords: Acute Respiratory Syndrome; Virosis; Coronavirus Infections; Pandemics; Neonates.

Artículo recibido: 05 de Mayo 2021 Aceptado para publicación: 20 de Junio 2021 Correspondencia: investigacionsrs@gmail.com Conflictos de Interés: Ninguna que declarar 


\section{INTRODUCCIÓN}

Desde la declaración de la pandemia por la OMS el 11 de Marzo de 2020, la literatura científica ha mostrado que al parecer los casos de COVID 19 en pediatría tienen una baja incidencia(Mimouni et al., 2020). Dentro de la población pediátrica hay una especial preocupación por los casos en población neonatal (0-28 días de vida) ya que se considera que son especialmente vulnerables dada su inmadurez inmunológica y características fisiológicas especiales, sin embargo la incidencia y morbimortalidad asociada por la infección SARS-Co-V-2 en neonatos aún no es clara(Mimouni et al., 2020).

Hasta el momento no hay evidencia concluyente de transmisión vertical, la mayoría de casos se presentan por contacto con un caso probado de COVID19; el cuadro clínico en recién nacidos es inespecífico(Shalish, Lakshminrusimha, Manzoni, Keszler, \& Sant'Anna, 2020) (Trevisanuto et al., 2020). Sin embargo, se considera que tiene el riesgo de generar una enfermedad grave, especialmente en prematuros.

La mayoría de artículos revisados sobre población pediátrica reportan pocos casos en neonatos y los incluyen en el grupo de población menor de un año y los que hacen referencia a población neonatal se centran en las gestantes con infección comprobada y sus recién nacidos, de los cuales en la gran mayoría no se demostró infección por infección SARS-Co-V-2(Mimouni et al., 2020) (Macías-Avilés HA, 2020) (Trevisanuto et al., 2020).

En la población pediátrica los datos sobre la ruta de contaminación, susceptibilidad, hallazgos clínicos, patogénesis, tratamiento farmacológico y pronóstico son limitados. Los niños pueden adquirir el virus a través de contacto directo, gotas, aerosoles e incluso la ruta fecal-oral(Oval1, 2020).

En uno de los estudios realizados en población pediátrica con 2143 casos, el 90\% fueron de asintomáticos a moderados, sin embargo la proporción de casos críticos y severos fue en menores de un año (10.6\%), mucho mayor que en niños mayores: 1-5 años (7.3\%), 614 años (4.2\%), 15 años (3\%) lo que sugiere que tienen un mayor riesgo de falla respiratoria(De Rose et al., 2020).

En los exámenes de laboratorio son típicos la leucopenia y linfopenia, mientras que los niveles de PCR y pro calcitonina generalmente son normales, otros hallazgos incluyen trombocitopenia leve, aumento en la creatinquinasa, fosfatasa alcalina, transaminasas y LDH. Las lesiones pulmonares se observan más claramente en la TAC que en la 
radiografía, se observan opacidades en vidrio esmerilado, consolidaciones múltiples lobares y segmentarias, particularmente en la periferia(De Rose et al., 2020)

En un reporte del CDC en Estados Unidos encontró que de 149.760 casos confirmados de COVID-19, de los cuales el 1.7\% eran niños menores de 18 años y el 0,3\% (398 casos) correspondían a menores de un año un año (95). Aunque los casos de COVID 19 pediátricos parecen ser bajos, la incidencia exacta y la morbimortalidad asociada por la infección SARS-Co-V-2 en neonatos no es clara(Shalish et al., 2020)

El virus se encontró en las secreciones nasofaríngeas hasta por 22 días y en heces hasta 30 días, las coinfecciones fueron bastante frecuentes (79\%) generalmente por micoplasma e Influenza, hasta un 35\% de los niños eran asintomáticos(Zimmermann \& Curtis, 2020) Los síntomas más frecuentes fueron tos (48\%), fiebre (42\%) y faringitis (30\%), también presentaron congestión nasal, rinorrea, taquipnea, sibilancias, diarrea, vómito, dolor de cabeza y fatiga. Los laboratorios tuvieron una mínima alteración, los hallazgos radiológicos fueron inespecíficos e incluyeron infiltrados uní o bilaterales, opacidades en vidrio esmerilado o consolidación. Los niños raramente necesitaron ingresar a unidad de cuidado intensivo (3\%) y el número de muertes ha sido mínimo. El $6 \%$ de los niños requirieron tratamiento con oxígeno, otros tratamiento usados fueron oseltamivir, riba virina, interferón, corticoides, inmunoglobulina y antibióticos, con una estancia hospitalaria de 5 a 28 días, con un promedio de 13-14 días(Zimmermann \& Curtis, 2020) Se han propuesto varias teorías para explicar porque en comparación con los adultos los niños con infección por SARS-CoV-2 tienen síntomas clínicos leves y menos anormalidades de laboratorio y radiológicas: Los niños tienen niveles más altos de receptor ECA2 pero al parecer con una menor afinidad por el virus que los adultos; tienen respuestas inmunes más fuertes, con una mayor proporción de linfocitos y de números absolutos de células T, B y Natural Killer lo que puede ayudarlos a combatir el virus, aunque se considera que tienen un sistema inmune inmaduro para otros virus respiratorios, lo que sugiere que la inmunidad protectora contra el SARS-CoV-2 es diferente de la otros virus respiratorios comunes(Oval1, 2020) (Zimmermann \& Curtis, 2020). Respuesta de citoquinas menos pro inflamatoria y menor tendencia a desarrollar SDRA. Menor prevalencia de comorbilidades asociadas a enfermedad severa(Yang et al., 2020) Los coronavirus circulantes son frecuentes en este grupo de edad por lo que pueden tener inmunidad cruzada protectora, tienen mayor colonización de la mucosa del tracto 
respiratorio por virus y bacterias lo que puede limitar la colonización y el crecimiento del SARS-CoV-2. Al ser infectados por un adulto lo que significa que son infectados por una segunda o tercera generación del virus, las cuales en SARS y MERS CoV se asociaron a una menor patogenicidad(Yang et al., 2020)

Al parecer los hallazgos clínicos en niños difieren entre países, en Europa y Asia la enfermedad ha sido más leve mientras en Estados Unidos hay más casos de requerimiento de ventilación mecánica, se ha sugerido que esto podría deberse a las diferencias en la vacunación contra el Bacilo de Calmette-Guérin, que puede tener efectos inmunomoduladores que afectan la respuesta inmune al SARS-CoV-2(Zimmermann \& Curtis, 2020).

Aún no hay certeza si los niños asintomáticos pueden transmitir el virus y si actúan como reservorios para el SARS-CoV-2, sin embargo se ha reportado que los niños aún los asintomáticos pueden tener altas cargas virales y excretar el virus en heces por períodos prolongados(Zimmermann \& Curtis, 2020)

Aún no es claro el efecto de la infección en la gestación, no se conocen las consecuencias de la infección en el primer trimestre, no se sabe si pueda causar ocasionar malformaciones, anomalías del crecimiento, disrupción de la maduración, pérdida fetal, abortos o causar parto pre término y aunque no hay evidencia de transmisión vertical las infecciones maternas se han asociado con retraso en el crecimiento, parto pre término y muertes perinatales, pero no es claro si estas complicaciones son debidas al virus ya que no está claro como la infección por COVID 19 en las madres afecta el estado fisiológico de los recién nacidos(Zimmermann \& Curtis, 2020) (Mimouni et al., 2020).

La leche maternal se considera segura contra infecciones virales ya que tiene componentes protectores como inmunoglobulinas y otros compuestos bioactivos; puede contener anticuerpos contra SARSCoV2 en madres infectadas pero aún no hay datos al respecto(Oval1, 2020).

En una revisión de series de casos de infección en la gestación con 65 gestantes y 67 neonatos, el 3\% de las madres tuvieron que ingresar a cuidado intensivo, se reportó sufrimiento fetal en $30 \%$ de las gestaciones, $37 \%$ de partos pre término. Las complicaciones neonatales incluyeron dificultad respiratoria o neumonía en un 18\%, bajo peso al nacer en 13\%, coagulación intravascular diseminada en 3\%, asfixia en $2 \%$ y 2 muertes perinatales. No se logró aislar el virus del líquido amniótico, tejido placentario, 
flujo vaginal, sangre del cordón o leche materna; 4 de los neonatos tuvieron PCR positiva para SARS-Co-V-2, de los cuales 3 presentaron neumonía a pesar de los estrictos procedimientos de control y prevención de la infección durante el parto y la separación de la madre, por lo que consideran no se puede excluir la transmisión vertical(Zimmermann \& Curtis, 2020).

En un estudio con 33 neonatos con madres con COVID-19 en Wuhan, China, los síntomas clínicos de los 33 neonatos fueron favorables. Se comprobó la infección en 3 (9\%) de los 33 pacientes en riesgo, de los cuales 2 fueron pacientes a término con síntomas inespecíficos (letargia, fiebre y dificultad para respirar), con imágenes radiológicas sugestivas de neumonía, exámenes de laboratorio inespecíficos (leucocitosis, linfopenia) e hisopados nasofaríngeos y rectales positivos por SARS-CoV-2 al 2 y 4 día de vida y negativos al 6 día. El neonato más grave tenía 31 semanas y nació por cesárea por sufrimiento fetal agudo (la madre tenía neumonía por COVID-19) y sus síntomas pueden estar relacionados con la prematurez, asfixia y sepsis más que por la infección por SARS-CoV-2. No pudieron descartar que la transmisión fuera vertical(Zeng et al., 2020). En un estudio de 7 gestantes y sus bebés, en el cual se monitorizaron 5 de los recién nacidos, no se encontraron síntomas, los hemogramas fueron normales, algunos tenían una leve elevación de la fracción MB de la creatin quinasa y del dímero D. Aún no se ha comprobado la transmisión vertical, en este caso se encontró que la condición de los recién nacidos no se agravo por su exposición a la infección por SARS-CoV-2 en las madres(Yang et al., 2020).

En la revisión con mayor número de casos de neonatos se evaluaron 44 recién nacidos, todos con infección por SARS-Co-V2 confirmada por hisopado nasofaríngeo o rectal con RT PCT positiva o por niveles altos de Inmunoglobulina $\mathrm{M}$ en 3 de los pacientes. De estos la tercera parte ingresaron desde sus hogares, los demás se hospitalizaron al nacer, la mitad tuvieron contacto con madre sintomática con infección por coronavirus, El 32\% fueron asintomáticos, los demás tuvieron síntomas leves típicos de infección respiratoria aguda (fiebre en un 50\%, hipoxemia en $20 \%$ y tos en 20\%) y/o síntomas gastrointestinales en un $20 \%$. La mayoría no requirió oxígeno suplementario (75\%) y egresaron en buenas condiciones después de un promedio de 10 días de hospitalización(Trevisanuto et al., 2020). 
En general los recién nacidos cuyas madres son positivas para infección por SARS-CoV2 tienen desenlaces favorables, no hay datos convincentes de transmisión vertical. En los pocos casos en que los recién nacidos han tenido prueba positiva el curso postnatal no tuvo complicaciones(Shalish et al., 2020).

En la población neonatal la infección por SARS-CoV-2 puede empezar de manera insidiosa, generalmente hay historia de contacto con un caso probado de COVID19 (generalmente la madre o miembros de la familia, cuidadores, personal médico y visitantes); el diagnóstico se confirma por la presencia de ácidos nucleicos del virus en la RT-PCR, pueden aislarse del tracto respiratorio superior, aspirado endotraqueal, sangre o heces(Shalish et al., 2020).

La proporción de neonatos con la enfermedad es extremadamente baja, el COVID 19 neonatal parece adquirirse postnatalmente y se asocia con desenlaces respiratorios favorables(Shalish et al., 2020).

En China en un reporte de 6 pacientes presentaron síntomas no específicos, no requirieron intubación y fueron dados de alta después de una completa recuperación(Shalish et al., 2020) (X. Ma, Zhu, \& Du, 2020). Los hallazgos clínicos son inespecíficos en los recién nacidos, la temperatura corporal puede ser alta, normal o baja, pueden tener síntomas respiratorios como tos, taquipnea, apnea, quejido aleteo nasal y taquicardia al igual que letargia, vómito, diarrea y distensión abdominal(Ovalı, 2020).

Se han descrito signos tempranos y tardíos. En la primera semana: Cambios en la temperatura (hipotermia, hipertermia); Respiratorio: signos de dificultad respiratoria que puede ir desde la forma leve hasta la más grave; Cardiovascular: taquicardia, bradicardia, hipotensión arterial, datos de choque; Alimentación y gastrointestinal: hiporexia, vómito, distensión abdominal, diarrea y Otros: letargia, hipo actividad. De la 1 a 3 semanas: rash, síntomas gastrointestinales, sepsis neonatal tardía, choque séptico y miocarditis(MacíasAvilés HA, 2020).

No hay hallazgos de laboratorio específicos, deben ser usados para evaluar la evolución del paciente, los leucocitos pueden ser normales o elevados o los linfocitos pueden estar disminuidos. Puede encontrarse trombocitopenia leve, leves elevaciones de la creatinquinasa, fosfatasa alcalina, transaminasas y lactato deshidrogenasa, incremento de biomarcadores cardiacos (CPK, troponina, péptido natri urético tipo $\mathrm{B}$ ), incremento de dímero D y ferritina. 
Dentro de las imágenes en la Radiografía de tórax o ultrasonido pulmonar es probable que muestren datos sugestivos de neumonía y la radiografía de abdomen puede mostrar datos de íleo(Macías-Avilés HA, 2020).

El panel para virus respiratorios del tracto respiratorio alto y bajo está indicado cuando el neonato ingresa de su casa con sintomatología respiratoria y es sospechoso de infección por COVID-19, esto con la finalidad de evaluar la presencia de otros agentes virales; el SARS-CoV-2 se puede mezclar con otros agentes patógenos como influenza A, influenza B, virus sincitial respiratorio y virus de Epstein Barr(Ovalı, 2020) (Macías-Avilés HA, 2020).

El Neonato confirmado y sintomático debe permanecer en una incubadora, con medidas de aislamiento de contacto y por gotas, el manejo general requiere de monitoreo estricto (frecuencia cardíaca y respiratoria, saturación de oxígeno, temperatura, presión arterial, glucemia) y vigilancia clínica. Se debe realizar RT-PCR para SARS-CoV-2, biometría hemática, PCR, pruebas de función renal, hepática, biomarcadores cardíacos, radiografía de tórax y abdomen(Shalish et al., 2020).

El aporte de líquidos y electrólitos intravenosos debe ser cauteloso para evitar o agravar el edema pulmonar; debe administrarse oxígeno suplementario para evitar la hipoxia(Gallegos Sandra., 2007). El sistema respiratorio es el más vulnerable, por lo que es indispensable implementar un sistema de apoyo respiratorio con prácticas seguras que incluyen: aislamiento adecuado del paciente, equipo de protección personal óptima y uso de filtros virales en los circuitos de los dispositivos de ventilación invasiva o no invasiva. El neonato con síndrome de dificultad respiratoria grave debe colocarse en posición prona tres o cuatros veces al día, suministrar dosis altas de surfactante pulmonar exógeno, CPAP, alto flujo, ventilación convencional, ventilación oscilatoria de alta frecuencia (VAFO) óxido nítrico inhalado.

Hasta el momento no existe un fármaco comprobado en contra del COVID-19, se debe evitar el uso inapropiado de antibióticos, especialmente antibióticos de amplio espectro y si existe evidencia de infección bacteriana secundaria, se deben usar antibióticos cautelosamente y no hay evidencia que respalde la efectividad de la gammaglobulina, el interferón o terapia hormonal(Oval1, 2020) (Macías-Avilés HA, 2020) (De Rose et al., 2020) (Shalish et al., 2020) (Lu \& Shi, 2020). 
Puede iniciarse la vía enteral lo más pronto posible, no hay duda de que la leche humana proporciona paso de anticuerpos al neonato contra SARS-CoV-2, aunque una madre COVID positiva representa mayor riesgo de contagio al recién nacido, por el contacto de gotas respiratorias generadas por ella. Por esto, de continuar la lactancia debe insistirse en las medidas de protección Se recomienda lactancia materna directa, extremando medidas de protección de la madre (mascarilla, lavado de manos, lavar senos con agua, jabón y una tela suave antes de amamantar o extraer la leche si ha tosido o estornudado sobre ellos y limpieza y desinfección de superficies, entre otras)(Ministerio de Salud y Protección Social. Instituto Nacional de Salud., 2020).

Si la madre es sintomática y no se siente bien para amamantar o presenta enfermedad grave se recomienda que realice extracción de la leche, la cual puede suministrársele al bebé. Se debe capacitar a la madre y familia en técnicas de extracción con las recomendaciones mencionadas, almacenamiento y conservación de la leche materna y forma de ofrecer al bebé el alimento con vaso o cuchara(Ministerio de Salud y Protección Social. Instituto Nacional de Salud., 2020).

Se puede dar egreso cuando la temperatura sea normal por más de 3 días y haya disminución evidente de los síntomas. Antes del alta hospitalaria deben explicarse al cuidador todas las precauciones (asilamiento de personas o familiares de riesgo) y datos de alarma (irritabilidad, rechazo a la vía oral, datos de dificultad respiratoria, inestabilidad de la temperatura, etc.), seguimiento por vía telefónica o video llamada diaria en los siguientes 14 días posteriores al alta hospitalaria(Shalish et al., 2020).

Debido a la falta de información sobre esta enfermedad nueva con detalles desconocidos sobre la severidad del cuadro, presencia de complicaciones, tratamiento y desenlaces decidimos centrarnos en los recién nacidos con infección comprobada por RT-PCR positiva en aspirado nasofaríngeo, con el objetivo de describir sus características, curso clínico y desenlaces.

Para lograr este objetivo realizamos una revisión retrospectiva de las historias clínicas desde 1 de Junio hasta el 12 de enero 2021 de los recién nacidos (0-28 días de edad) y pacientes prematuros con una edad gestacional menor a las 44 semanas de edad corregida con una prueba de RT-PCR positiva para SARS-Co-V-2 en pacientes que consultaron a la Sub Red Integrada de Servicios de Salud Sur en Bogotá, Colombia. 


\section{ESTRATEGIAS METODOLÓGICAS}

Diseño: Estudio descriptivo, trasversal y retrospectivo basado en una serie de casos. Teniendo en cuenta el número de observaciones menor de $30(n=21)$ y el desconocimiento de la varianza poblacional, se requirió utilizar la desviación estándar de la muestra s y la distribución de probabilidad t.

Se estimó la Incidencia Acumulada e IC95\%, de los neonatos reportados con infección confirmada por SARS-CoV-2 de acuerdo a las diferentes categorías por peso al nacer, empleando como denominador la población neonatal estimada por proyecciones especificas en las localidades de referencia de la subred Sur, primer trimestre de 2020(DANE. 2019-2020).

Criterios de inclusión: Prueba de RT-PCR positiva para SARS-Co-V-2 en aspirado nasofaríngeo; Recién Nacidos a término con edad menor a 28 días; Recién Nacidos Pre término con edad corregida menor a 44 semanas de edad gestacional que consulte a urgencias o sea hospitalizado.

Criterios de exclusión: Edad cronológica mayor a 28 días y Edad corregida mayor a 44 semanas de edad gestacional

\section{RESULTADOS Y DISCUSIÓN RESULTADOS}

Se presenta una serie corta de Neonatos( $\mathrm{n}=21)$, con evidencia de COVID 19 en el periodo de tiempo comprendido desde la semana epidemiológica 23 ( 2 casos) hasta la semana 32 (un caso), con frecuencia variable: semana 26, 27, 28 y 31(1 caso por semana); Semana 29(4 casos), semana 30(4 casos). (Tabla anexo 1). De este grupo 16 requirieron manejo intrahospitalario y 1 se manejó ambulatoriamente. Durante el período de tiempo del estudio nacieron 1453 bebés en la institución fuente y se realizaron pruebas de COVID a 77 recién nacidos.

Es evidenciable la correlación entre Peso al nacer y Edad gestacional $(\mathrm{R}=0.86)$ (Gráfica uno). El promedio de edad de los neonatos es de 26,57 días (IC95\%: 16,26-36,87) (p= $0.27)$, con una estancia promedio de cinco $(5,5)$ días en aquellos con requerimiento de oxigeno domiciliario en siete neonatos, y de 3,9 días sin el requerimiento de oxígeno al egreso en diez (13) neonatos. La caracterización de la serie evidencia predominio del Grupo 0 Positivo y género masculino (73\%). 
Tabla 1. Antecedentes Obstétricos

\begin{tabular}{|l|c|c|c|c|}
\hline \multicolumn{1}{|c|}{ VARIABLE } & PROMEDIO & DE & MIN & MÁX \\
\hline Número de embarazos & 1,9 & 1.11 & 1 & 5 \\
\hline Número de Partos & 1.4 & 1.02 & 0 & 4 \\
\hline Número de Cesáreas & 0,3 & .74 & 0 & 3 \\
\hline Número de Hijos vivos & 1.7 & .88 & 1 & 4 \\
\hline Número de Abortos & .1 & .35 & 0 & 1 \\
\hline Número ectópicos & .04 & .21 & 0 & 1 \\
\hline Número controles Prenatales & 3.5 & 2.80 & 0 & 11 \\
\hline
\end{tabular}

Fuente: elaboración propia

Se registran como antecedentes obstétricos, madres con un número promedio de embarazos de 1,9 y un promedio de controles de 3,5 (DE: 2,8) (Tabla 1), siendo reporte de fruto de madre adolescente en dos casos. Aun cuando el $81 \%(n=17)$ de los niños recibieron lactancia materna, en un 57\%(n=9) se les administró lactancia complementaria con fórmula láctea.

Las manifestaciones clínicas evidenciables al ingreso son de temperatura promedio 36,59(Tabla 3), frecuencia cardíaca (154), frecuencia respiratoria $(42,47)$ y valores de llenado capilar adecuados $(\mathrm{p}=\mathrm{o}, 10)$.

Tabla 2. Cuadro clínico Neonatal

\begin{tabular}{|l|c|c|c|c|}
\hline \multicolumn{1}{|c|}{ VARIABLE } & PROMEDIO & EE & IC 95\% & $\begin{array}{c}\text { VALOR } \\
\text { P }\end{array}$ \\
\hline Frecuencia cardiaca & 154 & 3,00 & $147,7-160,3$ & 0,00 \\
\hline Frecuencia Respiratoria & 42,47 & 1,26 & $39,8-45,1$ & 0,00 \\
\hline Presión sistólica & 83,61 & 2,88 & $77,6-89,6$ & 0,00 \\
\hline Presión Diastólica & 50,23 & 1,43 & $47,2-53,2$ & 0,00 \\
\hline Saturación oxígeno en habitación & 72,9 & 7,95 & $56,3-89,5$ & 0,00 \\
\hline Saturación oxigeno con apoyo & $76 ., 33$ & 8,29 & $59,0-83,6$ & 0,00 \\
\hline
\end{tabular}

Fuente: elaboración propia 
Al evaluar el peso al nacer y la edad gestacional $(r=0,86)$, se evidencia distribución asimétrica en Dificultad Respiratoria y el requerimiento de oxigeno suplementario (Ilustración 1 y 2).

Ilustración 1. Síndrome dificultad respiratoria VS peso al nacer

Ilustración 2. Oxígeno suplementario VS peso al nacer

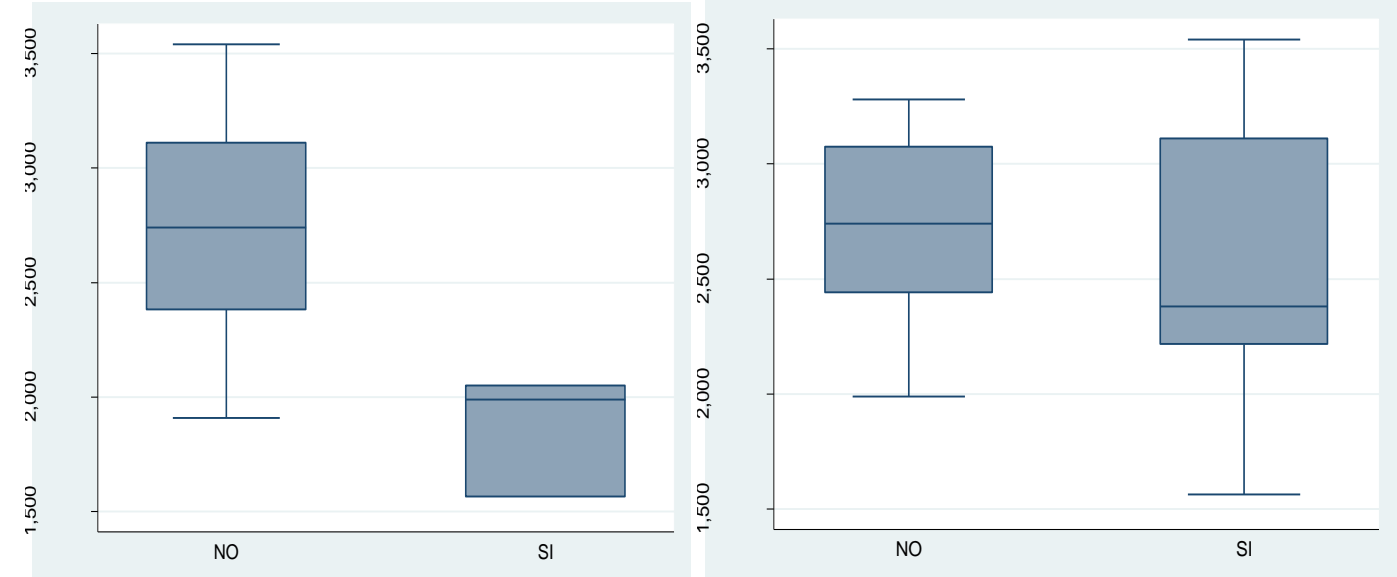

Fuente: elaboración propia

La principal causa de ingreso (Tabla 3 ) fue Bronquiolitis $(n=8)$ y como causa secundaria al ingreso se evidencio anemia de la prematuridad $(n=1)$, bronquiolitis $(n=1)$, sospecha de Coronavirus $(n=1)$ e Infección respiratoria aguda leve (equivalente a influenza) $(n=4)$. Dentro de la sintomatología encontramos que la mayoría $(71.4 \%)$ presentaba síntomas respiratorios (dificultad respiratoria, rinorrea, congestión nasal, estornudos) y/o cianosis, la fiebre no fue un hallazgo tan común estando presente en sólo 5 de los pacientes $(23.85 \%)$ y 2 de los pacientes presentaron apneas (ambos pacientes tenían antecedente de prematurez).

Se evidencio contacto cercano con personas con síntomas respiratorios o fiebre en 11 de los pacientes $(52.3 \%)$, y en un caso aunque los familiares se encontraban asintomáticos, tenía contacto con una persona que trabajaba en Central de abastos, lugar en el que se presentó un brote de la enfermedad. 
Tabla 3. Perfil neonatal

\begin{tabular}{|l|c|c|c|}
\hline \multicolumn{1}{|c|}{$\begin{array}{c}\text { Perfil Morbilidad } \\
\text { Ingreso }\end{array}$} & Frecuencia & Porcentaje & Acumulado \\
\hline $\begin{array}{l}\text { Riesgo Infección SARS-CoV-2(Madre con } \\
\text { síntomas gripales y fiebre) }\end{array}$ & 1 & 4.76 & 4.76 \\
\hline Bronquiolitis & 8 & 38.10 & 42.86 \\
\hline Bronquiolitis aguda no especificada. & 1 & 4.76 & 47.62 \\
\hline Celulitis de la cara & 1 & 4.76 & 52.38 \\
\hline Cianosis & 1 & 4.76 & 57.14 \\
\hline Coronavirus como causa de enfermedad cl & 1 & 4.76 & 61.90 \\
\hline Ictericia Neonatal no especificada. & 1 & 4.76 & 66.67 \\
\hline Infección por coronavirus no especifica & 2 & 9.52 & 76.19 \\
\hline Infección Respiratoria aguda leve & 1 & 4.76 & 80.95 \\
\hline Rinofaringitis aguda & 2 & 9.52 & 90.46 \\
\hline Sepsis neonatal & 2 & 9.52 & 100 \\
\hline & & & \\
\hline Total & 21 & 100.00 & \\
\hline & & & \\
\hline
\end{tabular}

\section{Fuente: elaboración propia}

Las Pruebas diagnósticas realizadas (Tabla 4) fueron RT-PCR positiva para SARS-Co-

V-2 en aspirado nasofaríngeo en 21 pacientes; Hemograma en 19 pacientes y Proteína C Reactiva en 15 pacientes

Tabla 4. Pruebas Hematológicas

\begin{tabular}{|l|c|c|c|c|}
\hline \multicolumn{1}{|c|}{ VARIABLE } & PROMEDIO & DE & IC 95\% & valor P \\
\hline Hemoglobina & 13,27 & 1,29 & $10,7-15,7$ & 0,89 \\
\hline Hematocrito & 40,31 & 23.33 & $5,4-86,0$ & 0,98 \\
\hline leucocitos & 10643,1 & 5864.7 & $\begin{array}{c}851,1- \\
22137,9\end{array}$ & 0,99 \\
\hline Neutrófilos & 28,4 & 21.22 & $13,1-69,9$ & 0,99 \\
\hline Linfocitos & 37.09 & 29.09 & $\begin{array}{c}19,9- \\
94,1\end{array}$ & 0,99 \\
\hline Monocitos & 12,11 & 1,57 & $9,0-15,1$ & 0,94 \\
\hline
\end{tabular}




\section{Fuente: elaboración propia}

El reporte PCR en los recién nacidos presento un Promedio 0,32 (DE: 0,34) evidenciando desviación a la izquierda en 15 de los recién nacidos.

La estimación de la incidencia acumulada se realiza a partir del análisis de los Neonatos con infección por SARS-CoV-2 diagnosticados entre el 1 de junio al 30 de agosto, quienes recibieron atención hospitalaria en La subred integrada de servicios de salud.

Se registró en el periodo de 2020, 15797 nacidos vivos en el área de influencia de la institución, lo que arroja una incidencia neonatal de infección por SARS-CoV-2 de 1, 16 (IC del 95\%: 1-2) por 10000 nacidos vivos y a nivel institucional ( $\mathrm{n}=1453$ recién nacidos) en el periodo de tiempo de junio a agosto del 2020) de 11,7(7,3-18,7) por 1000 nacidos vivos.

Tabla 5. Incidencia Acumulada Infección Neonatal por SARS-CoV-2 Junio-Agosto 2020

\begin{tabular}{|c|c|c|c|}
\hline $\begin{array}{c}\text { Grupo Peso al } \\
\text { Nacer }\end{array}$ & Frecuencia & $\begin{array}{c}\text { No Casos } \\
\text { Covid 19 }\end{array}$ & $\begin{array}{c}\text { Incidencia Acumulada } \\
(\text { Ic 95\% })\end{array}$ \\
\hline$>1000$ Grs & 63 & - & - \\
\hline $1000-1499$ & 126 & - & $0,0106(0,0036-0,0306)$ \\
\hline $1500-1999$ & 284 & $3(17,6 \%)$ & $0,0058(0,0026-0,0125)$ \\
\hline $2000-2499$ & 1042 & $6(35,2 \%)$ & $0,0007(0,0002-0,0020)$ \\
\hline $2500-2999$ & 4449 & $3(17,6 \%)$ & $0,0006(0,0002-0,0015)$ \\
\hline $3000-3499$ & 6739 & $4(23,52 \%)$ & $0,0004(0,0001-0,0021)$ \\
\hline $3500-3999$ & 2699 & $1(5,88 \%)$ & - \\
\hline $4000 \mathrm{y}+$ & 395 & - & $0,0117(0,0073-0,0187)$ \\
\hline Total & & 17 & \\
\hline
\end{tabular}

Fuente: elaboración propia

\section{DISCUSIÓN}

De manera global las series de casos encontradas incluyen a los neonatos con toda la población pediátrica evidenciando por ejemplo, en un total de 333 niños entre 1 día -17 años de edad el $83 \%$ de los niños tenían historia de contacto positivo, generalmente con miembros de la familia, con un período de incubación de 2-25 días con un promedio de 7(Been, Lievense, Zimmermann, Kramer, \& Wolfs, 2013). 
Desde el inicio de la pandemia hasta la semana epidemiológica 25, se han confirmado 42 casos de COVID-19 en neonatos, 23 masculinos y 19 femeninos, el 52,4\% se concentra en Bogotá, Barranquilla y Boyacá (Tunja). Según la fuente de contagio el 21,4\% se clasifican como relacionados y la entidad territorial con el mayor porcentaje de casos en estudio es Bogotá (24,2 \%) seguido por Barranquilla (21,2\%) y Nariño (15,2 \%)(Instituto Nacional de Salud, 2020).

La institución donde se realiza el estudio es de origen público, atiende a población perteneciente al régimen de salud subsidiado, con un alto porcentaje de población migrante $(29.9 \%)$ y de prematurez $(10 \%)$ durante el período del estudio. Cuenta con una Unidad de Cuidado Neonatal con 70 camas y un Programa Canguro que realiza en promedio 560 consultas mensuales de Pediatría.

En esta serie de casos podemos observar que hay un leve predominio del género masculino con el $52 \%$ de todos los casos, la presencia de una prueba positiva se correlaciona con el peso al nacer y con la edad gestacional, ya que 10 pacientes pertenecían al programa canguro $(58,8 \%)$, es decir que su peso al nacer era $2500 \mathrm{~g}$ y/o tenían una edad gestacional $<$ a 37 semanas.

De los 4 pacientes que no presentaron síntomas respiratorios 2 se encontraban asintomáticos (a uno se le tomó la prueba por la presencia de varios casos de COVID en el núcleo familiar), 1 consultó por celulitis peri orbitaría y otro fue remitido de plan canguro por sospecha de anemia (palidez mucocutánea). El 52.9\% tenían como noción de contagio la presencia de un familiar con síntomas respiratorios, cefalea o fiebre, 5 tenía antecedente de haber estado hospitalización al nacer y ninguno había realizado viajes a áreas con casos documentados de COVID. Dentro de los hallazgos al examen físico el más frecuente fue la presencia de desaturación, con una saturación promedio sin oxígeno suplementario de $84 \%$, los otros signos vitales fueron normales al igual que la perfusión distal, lo que indica que ningún paciente presentaba un compromiso severo a su ingreso. En el hemograma la única alteración encontrada fue la presencia de monocitosis con un promedio de monocitos del 12,11\% (IC 9,0-15,1), la PCR no mostró alteraciones, siendo negativa con un valor promedio de 0.32 (Punto de corte: positiva > 0.4).

Ninguno de los pacientes estuvo en estado crítico, sólo requirieron oxígeno suplementario con oxígeno en cánula nasal a bajo flujo, no necesitaron intubación oro traqueal, ventilación mecánica o uso de inotropia, sólo en 5 de los pacientes se usó manejo 
antibiótico (1 por sospecha de infección por parto extra hospitalario, 1 por celulitis peri orbitaría, 1 por infección urinaria y 2 por sospecha de sepsis neonatal tardía).

Los hallazgos son concordantes con la evidencia actual, aunque los niños al parecer tienen síntomas menos severos al infectarse, el riesgo potencial de esta nueva enfermedad permanece desconocida en neonatos, especialmente en prematuros, quienes necesitan una observación estricta y cautelosa ya que tienen mayor riesgo de presentar síntomas insidiosos e inespecíficos como letargia o deshidratación(Zimmermann \& Curtis, 2020). El Neonato confirmado y sintomático debe permanecer en una incubadora, con medidas de aislamiento de contacto y por gotas, el manejo general requiere de monitoreo estricto (frecuencia cardíaca y respiratoria, saturación de oxígeno, temperatura, presión arterial, glucemia) y vigilancia clínica. Se debe realizar RT-PCR para SARS-CoV-2, biometría hemática, PCR, pruebas de función renal, hepática, biomarcadores cardíacos, radiografía de tórax y abdomen. Casi la mitad de los pacientes $(41,7 \%)$ requirió oxígeno domiciliario para el egreso y hubo correlación entre el peso al nacer y la edad gestacional con la necesidad de requerir oxígeno en la hospitalización y al egreso.

La estimación de la incidencia neonatal de infección por SARS-CoV-2 de 1, 16 (IC del 95\%: 1-2) por 10000 nacidos vivos es baja y menor con los hallazgos en etapa previa(1 de marzo y 30 de abril de 2020), en un entorno nacional en el que se estimó que hubo 118347 nacidos vivos, lo que arroja una incidencia neonatal de infección por SARS-CoV2 de $5 \cdot 6$ (IC del 95\%: 4 · 3-7 · 1) por 10000 nacidos vivos(Gale et al., 2021).

La incidencia específica de Inglaterra fue de 6,4 (IC 95\%: 4, 9-8, 2) por 10000 nacidos vivos. En el Reino Unido, 28 bebés cumplieron los criterios de infección pediátrica grave por SARS-CoV-24 (incidencia 2, $4(1,6-3,4)$ por 10000 nacimientos; los diagnósticos neonatales alcanzaron su punto máximo a principios de abril, encontrando la mediana de edad al momento del diagnóstico de 9,5 días (IQR 7,5-11,0) y 45 (68\%) bebés fueron diagnosticados más de 7 días después del nacimiento, hallazgo menor a nuestra serie(Gale et al., 2021).

En contraste con el comportamiento epidemiológico homogéneo de la incidencia en Reino Unido, se ha publicado la heterogeneidad del indicador en el País de inicio en la pandemia, con reporte marginal en población neonatal. La incidencia acumulada de COVID-19 en la provincia de Henan fue de 1,32 / 100 000, la tasa de curación fue del $98,03 \%$ y la tasa de letalidad fue del $1,73 \%$ al 9 de marzo de 2020. 
La curva de incidencia mostró que el pico epidémico alcanzó el 24 de enero a enero. 28. La zona de alta incidencia fue Xinyang, con una tasa de incidencia acumulada estandarizada de 4,36 / 100 000. La incidencia de varones fue de 1,41 / 100 000, mientras que la incidencia de mujeres fue de 1,23 / 100 000. La edad con mayor incidencia de COVID-19 en la provincia de Henan fue de 20 a 69 años $(88,68 \%)$. La tasa de incidencia fue más alta en hombres de 30 a 39 años (2,51 / 100 000), mientras que la tasa más baja fue en mujeres de 0 a 9 años $(0,16$ / 100 000)(Q. Ma, Li, Zhai, Gao, \& Zhao, 2020).

\section{CONCLUSIÓN O CONSIDERACIONES FINALES}

En los pacientes neonatos de esta serie de casos se observó que en su mayoría con infección por SARS Co-V-2 hay presencia de síntomas respiratorios leves e hipoxemia, aunque hay algunos pacientes que son asintomáticos. En general el curso clínico es favorable, presentando cuadros leves que requieren básicamente manejo sintomático. En niños prematuros y/o de bajo peso al nacer, aunque la enfermedad continúa siendo leve hay una mayor posibilidad de requerir oxígeno suplementario y su continuidad al momento del egreso.

Al no disponer de niveles superiores de evidencia en los diferentes aspectos de padecimiento de COVID 19 en neonatos, se ejecutó un diseño de series de casos(Murad MH, Sultan S, Haffar S, 2018), que permite describir una novel patología en un grupo poblacional altamente vulnerable. Se ha controlado el posible sesgo de selección al realizar una descripción explicita de la totalidad de los casos en un periodo de tiempo específico. A nivel de la determinación o verificación se evitó el auto informe y se emplearon solo registros clínicos a partir de aplicación de un Registro institucional validado y estandarizado, que permite determinar adecuadamente tanto la exposición como el resultado.

Finalmente, para el dominio de la causalidad, se tiene una inferencia más fuerte, al controlar otras causas alternativas que pudiesen explicar la observación. No se documentaron fenómenos de re exposición y el seguimiento se garantizó mediante controles en el periodo de junio de 2020 a abril 2021. El informe de los casos, tiene una descripción amplia y detallada que contribuye a la aplicación de las inferencias expuestas(Lee et al., 2011), en la toma de decisiones en práctica clínica Neonatal.

Finalmente, aun cuando en este tipo de diseño no se producen medidas de asociación, se proporciona la estimación de Incidencia Acumulada con precisión asociada. 
ANEXOS

Tabla Anexo 1. Inicio de primer síntoma por semana epidemiológica

\begin{tabular}{|c|c|c|c|c|}
\hline $\begin{array}{c}\text { Fecha Inicio } \\
\text { Sintomatologia }\end{array}$ & Frecuencia & Porcentaje & Acumulado & $\begin{array}{c}\text { Semana } \\
\text { Epidemiologica }\end{array}$ \\
\hline $05 / 06 / 2020$ & 1 & 4.76 & 4.76 & $23-2020$ \\
\hline $06 / 06 / 2020$ & 1 & 4.76 & 9.52 & $23-2020$ \\
\hline $25 / 06 / 2020$ & 1 & 4.76 & 14.29 & $26-2020$ \\
\hline $03 / 07 / 2020$ & 1 & 4.76 & 19.05 & $27-2020$ \\
\hline $05 / 07 / 2020$ & 1 & 4.76 & 23.81 & $28-2020$ \\
\hline $12 / 07 / 2020$ & 1 & 4.76 & 28.57 & $29-2020$ \\
\hline $14 / 07 / 2020$ & 1 & 4.76 & 33.33 & $29-2020$ \\
\hline $17 / 07 / 2020$ & 1 & 4.76 & 38.10 & $29-2020$ \\
\hline $18 / 07 / 2020$ & 2 & 9.52 & 42.86 & $29-2020$ \\
\hline $19 / 07 / 2020$ & 1 & 4.76 & 47.62 & $30-2020$ \\
\hline $21 / 07 / 2020$ & 1 & 4.76 & 52.38 & $30-2020$ \\
\hline $22 / 07 / 2020$ & 1 & 4.76 & 57.14 & $30-2020$ \\
\hline $24 / 07 / 2020$ & 1 & 4.76 & 66.67 & $30-2020$ \\
\hline $28 / 07 / 2020$ & 1 & 4.76 & 71.43 & $31-2020$ \\
\hline $07 / 08 / 2020$ & 1 & 4.76 & 76.19 & $32-2020$ \\
\hline $12 / 08 / 2020$ & 1 & 4.76 & 80.95 & $33-2020$ \\
\hline $16 / 10 / 2020$ & 1 & 4.76 & 85.71 & $42-2020$ \\
\hline $17 / 12 / 2020$ & 1 & 4.76 & 90.48 & $51-2020$ \\
\hline $28 / 12 / 2020$ & 1 & 4.76 & 95.24 & $53-2020$ \\
\hline $12 / 01 / 2021$ & 1 & 4.76 & 100.00 & $2--2021$ \\
\hline Total & 21 & 100.00 & & \\
\hline
\end{tabular}

Fuente: Elaboración propia 


\section{Gráfica uno. Peso al nacer-Edad gestacional}

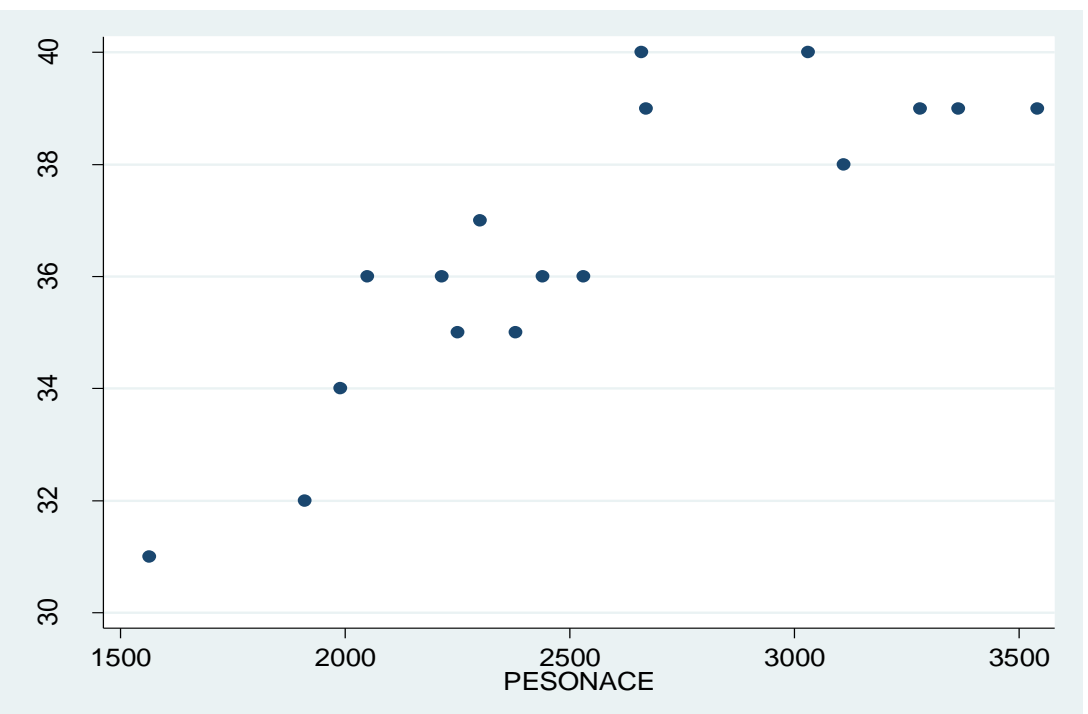

\section{LISTA DE REFERENCIAS}

Been, J. V., Lievense, S., Zimmermann, L. J. I., Kramer, B. W., \& Wolfs, T. G. A. M. (2013). Chorioamnionitis as a Risk Factor for Necrotizing Enterocolitis: A Systematic Review and Meta-Analysis. The Journal of Pediatrics, 162(2), 236242.e2. https://doi.org/10.1016/j.jpeds.2012.07.012

De Rose, D. U., Piersigilli, F., Ronchetti, M. P., Santisi, A., Bersani, I., Dotta, A., ... Auriti, C. (2020). Novel Coronavirus disease (COVID-19) in newborns and infants: what we know so far. Italian Journal of Pediatrics, 46(1), 56. https://doi.org/10.1186/s13052-020-0820-х

Gale, C., Quigley, M. A., Placzek, A., Knight, M., Ladhani, S., Draper, E. S., ... Kurinczuk, J. J. (2021). Characteristics and outcomes of neonatal SARS-CoV-2 infection in the UK: a prospective national cohort study using active surveillance. The Lancet Child \& Adolescent Health, 5(2), 113-121. https://doi.org/10.1016/S2352-4642(20)30342-4

Gallegos Sandra. (2007). Herramientas Para Promover La Estrategia de La Seguridad Del Paciente En El Sistema Obligatorio de Garantía de Calidad de La Atención En Salud. Bogotá. D.C.

Instituto Nacional de Salud. (2020). Situación COVID en neonatos: Colombia. Bogotá D.C. Retrieved from https://ascon.org.co/wp- 
content/uploads/2020/06/REV_Situacion_COVID_neonatoscolombia_18062020.pdf

Lee, W. A., Matsumura, J. S., Mitchell, R. S., Farber, M. A., Greenberg, R. K., Azizzadeh, A., ... Fairman, R. M. (2011). Endovascular repair of traumatic thoracic aortic injury: Clinical practice guidelines of the Society for Vascular Surgery. Journal of Vascular Surgery, 53(1), 187-192. https://doi.org/10.1016/j.jvs.2010.08.027

Lu, Q., \& Shi, Y. (2020). Coronavirus disease (COVID-19) and neonate: What neonatologist need to know. Journal of Medical Virology, 92(6), 564-567. https://doi.org/10.1002/jmv.25740

Ma, Q., Li, C., Zhai, Y., Gao, J., \& Zhao, J. (2020). Epidemic features of coronavirus disease 2019 in Henan Province. Zhong Nan Da Xue Xие Bao. Yi Xие Ban = Journal of Central South University. Medical Sciences, 45(5), 582-590. https://doi.org/10.11817/j.issn.1672-7347.2020.200213

Ma, X., Zhu, J., \& Du, L. (2020). Neonatal Management During the Coronavirus Disease (COVID-19) Outbreak: The Chinese Experience. NeoReviews, 21(5), e293-e297. https://doi.org/10.1542/neo.21-5-e293

Macías-Avilés HA. (2020). Manejo del neonato sospechoso e infectado de COVID-19 en la UCIN. Acta Pediatr Mex, 41(Suppl: 1), 101-108.

Mimouni, F., Lakshminrusimha, S., Pearlman, S. A., Raju, T., Gallagher, P. G., \& Mendlovic, J. (2020). Perinatal aspects on the covid-19 pandemic: a practical resource for perinatal-neonatal specialists. Journal of Perinatology, 40(5), 820826. https://doi.org/10.1038/s41372-020-0665-6

Ministerio de Salud y Protección Social. Instituto Nacional de Salud. Lineamientos Provisionales para la atención en salud de las gestantes, recién nacidos y para la lactancia materna, en el contexto de la pandemia de Covid-19 (2020). Colombia.

Murad MH, Sultan S, Haffar S, et al. (2018). Evidence-Based Medicine. BMJ EvidenceBased Medicine, 23, 60-63.

Oval1, F. (2020). SARS-CoV-2 Infection and the Newborn. Frontiers in Pediatrics, 8. https://doi.org/10.3389/fped.2020.00294

Shalish, W., Lakshminrusimha, S., Manzoni, P., Keszler, M., \& Sant'Anna, G. M. (2020). COVID-19 and Neonatal Respiratory Care: Current Evidence and Practical Approach. American Journal of Perinatology, 37(08), 780-791. 
https://doi.org/10.1055/s-0040-1710522

Trevisanuto, D., Cavallin, F., Cavicchiolo, M. E., Borellini, M., Calgaro, S., \& Baraldi, E. (2020). Coronavirus infection in neonates: a systematic review. Archives of Disease in Childhood - Fetal and Neonatal Edition, fetalneonatal-2020-319837. https://doi.org/10.1136/archdischild-2020-319837

Yang, P., Wang, X., Liu, P., Wei, C., He, B., Zheng, J., \& Zhao, D. (2020). Clinical characteristics and risk assessment of newborns born to mothers with COVID-19. $\begin{array}{lllll}\text { Journal of } \quad \text { Clinical } & \text { Virology, } & 127, & 104356 .\end{array}$ https://doi.org/10.1016/j.jcv.2020.104356

Zeng, L., Xia, S., Yuan, W., Yan, K., Xiao, F., Shao, J., \& Zhou, W. (2020). Neonatal Early-Onset Infection With SARS-CoV-2 in 33 Neonates Born to Mothers With COVID-19 in Wuhan, China. JAMA Pediatrics, 174(7), 722. https://doi.org/10.1001/jamapediatrics.2020.0878

Zimmermann, P., \& Curtis, N. (2020). COVID-19 in Children, Pregnancy and Neonates. The Pediatric Infectious Disease Journal, 39(6), 469-477. https://doi.org/10.1097/INF.0000000000002700 